\title{
Entre o letramento em games e a gamificação: as mecânicas em jogo
}

\author{
Aline Conceição Job da Silva ${ }^{1}$ \\ Programa de Pós-Graduação em Letras e Cultura, Universidade de Caxias do Sul - UCS, Caxias do Sul, RS, Brasil
}

Resumo: A gamificação, entendida como o uso de mecânicas de jogo em ambientes de não jogo, se coloca, atualmente, como uma solução engajadora para a aprendizagem em diferentes disciplinas e níveis educacionais. Não obstante, ela surgiu como uma iniciativa mercadológica para envolver as pessoas em ciclos de consumo por meio de motivação e recompensas a partir das mecânicas de jogo. Inserida no contexto brasileiro, a transposição da gamificação de contextos culturais educacionais do Norte Global não contempla aspectos particulares locais. Nesse sentido, este texto objetiva debater a ausência ou a capacitação insuficiente em letramento em games por parte de professoras e de professores e, também, algumas questões, possivelmente éticas, da aplicação da gamificação na educação. Para tanto, estabelece-se uma relação entre os conceitos de gamificação e de letramento em games a partir de referenciais teóricos e críticos sobre os temas.

Palavras-chave: Letramento em games; Gamificação; Videogames.

Title: Between Game Literacy and Gamification: the mechanics at play

Abstract: Gamification, understood as the use of game mechanics in non-gaming environments, is nowadays an engaging solution for learning in different subjects and educational levels. Nonetheless, it emerged as a marketing initiative to engage people in consumer cycles through motivation and rewards from the game mechanics. The transposition of gamification from educational cultural contexts of the Global North, inserted in the Brazilian context, does not contemplate particular local aspects. In this sense, this text aims to discuss the absence or the insufficiency of game literacy in teachers training and also some ethical questions about the use of gamification in education. For this purpose, a relationship is stablished between the concepts of gamification and game literacy from theoretical and critical references on the themes.

Keywords: Game literacy; Gamification; Video Games.

\footnotetext{
${ }^{1}$ Doutora em Letras - Teoria da Literatura (Pontifícia Universidade Católica do Rio Grande do Sul - PUCRS), Bolsista PNPD do Programa de Pós-Graduação em Letras e Cultura da Universidade de Caxias do Sul. Orcid: https://orcid.org/0000-0002-4399-6018

E-mail: alinecjob@gmail.com
} 


\section{Mecânica 1: Rolagem de dados}

Pode-se afirmar que gamificação não diz respeito à aplicação de jogos em ambientes de não jogo. Ou, ainda, que gamificação não trata, apenas, de transposição de variações do modelo de pontos-medalhas-rankings (HAMARI; KOIVISTO; SARSA, 2014) para experiências que não são de jogo. Esses são entendimentos inadequados, para dizer o mínimo, embora defensoras e defensores da gamificação tenham transposto dos games aquilo que é menos essencial para os jogos e representado como o núcleo da experiência (ROBERTSON, 2010): o tal modelo de pontos-medalhas-rankings.

É razoável pensar que falta uma certa consciência do que há por trás da gamificação num sentido mais simples, a saber, o design de jogo como a prática de criar interações agradáveis, por pessoas na área da educação, que se viram inseridas em um contexto de exigência de conhecimento de novas mídias e de novas estratégias de ensino que engajem e motivem estudantes.

Além da falta dessa consciência, pode-se afirmar, inclusive, que essas pessoas não refletiram sobre como o discurso e a aplicação da gamificação podem afetar as pessoas a longo prazo. Em princípio, professores e professoras podem ver na gamificação de sua sala de aula apenas novas formas para ensinar, motivar e avaliar suas turmas, mas desconsideram que o modelo pode trazer consequências para o convívio cotidiano que não foram previstas, uma vez que as camadas de jogo embutidas nisso podem gerar motivação a partir de coerção ou incentivo e frustrar, em vez de explorar, as características motivacionais na atividade de jogo (WALZ; DETERDING, 2014).

Não se pode perder de vista, também, que a gamificação surgiu como uma estratégia de negócio para o engajamento de consumidores de produtos e de serviços e os resultados dos usos permanecem atrelados, de forma bastante forte, aos programas de fidelidade (quanto mais você compra/usa, mais pontos você ganha para ter mais produtos, serviços ou capital simbólico), ao autoaperfeiçoamento por meio da análise do próprio comportamento (WOLF, 2009) e aos incentivos contínuos de atividades gamificadas para que o usuário ou a usuária se mantenha no ciclo de progressão.

Considerar essas colocações pode ser um dos pontos de partida para sujeitos que estão na posição de pensar o seu papel na educação no contexto atual, que enfatiza a necessidade de engajar estudantes com novas tecnologias. Ter essas noções e compreender que atividades envolventes precedem o uso da gamificação também podem contribuir para o fazer educacional de professoras e de professores, tendo em vista a situação talvez angustiante pelo duplo desconhecimento de jogo e de gamificação.

Nesse sentido, quando se pensa em letramento em games, deve-se pensar, antes, na ausência disso na formação de professoras e de professores e de que forma isso pode impactar nas suas práticas, considerando que o discurso da gamificação está presente em 
escolas e em universidades como forma de ensino e de aprendizagem para o século XXI. Quer dizer, como esperar que profissionais da educação gamifiquem a sua sala de aula se eles e elas conhecem pouco ou desconhecem o objeto que é o ponto de partida da gamificação? Não considerar o letramento em games por parte do corpo docente, em um contexto educacional que tem cobrado isso cada vez mais, seria o mesmo que, em uma aula de literatura, por exemplo, professores e professoras não conhecessem literatura ou não lessem livros.

Muito se fala em gamificação como uma solução engajadora para a aprendizagem e mais ainda em atividades gamificadas para o ensino, para diferentes disciplinas e níveis educacionais, que envolveriam estudantes de forma que essas e esses aprenderiam mais ou melhor a partir de estratégias desenvolvidas para as novas tecnologias. Esse discurso apresenta a ideia de que novas linguagens precisam de uma nova acomodação, um novo aprendizado. Tal aprendizado, ou letramento, pode significar o desenvolvimento da compreensão do videogame como um conjunto de linguagens que concorrem para formar significados na experiência de jogo e as mecânicas que são depreendidas podem, sim, tornar-se parte do arcabouço de estratégias de aprendizagem de diferentes pessoas. No entanto, esse discurso também carrega a ideia simplista de uso pelo uso de novas tecnologias, produzindo, inclusive, o entendimento de que gamificação é o uso de jogos (digitais) em contextos de não jogo.

Embora seja possível ler a definição tradicional de que "gamificação é o uso de elementos e mecânicas de jogo em ambientes de não jogo" em resumos de teses e de dissertações e mesmo em sinopses de livros sobre o tema publicados no Brasil, a sequência desses textos enfatiza pesquisas ou experiências de aplicação de jogos (analógicos ou digitais) em sala de aula. Para verificar isso, basta pesquisar os livros brasileiros no Google Books ou o Catálogo de Teses \& Dissertações da Capes, procurando por "gamificação" e "letramento de/em games", e, além disso, identificar que esses trabalhos não pensam no sujeito docente que terá que lidar com isso em sala de aula. São poucos os textos brasileiros que debatem criticamente essa situação (SANTAELLA; NESTERIUK; FAVA, 2018; FADEL; ULBRICHT; BATISTA; VANZIN, 2014).

Há por trás disso, também, a ideia de que jogos, especialmente os digitais, aproximariam estudantes dos ensinos fundamental e médio da aprendizagem pelo "interesse geracional" com as novas tecnologias. Outra falácia apresentada por defensoras e defensores da gamificação, pois: a distribuição demográfica de pessoas que jogam no Brasil não se concentra na faixa etária de 7 a 18 anos, mas na faixa entre 25 e 34 anos de idade (PGB, 2018); nem todas as pessoas (nessa ou em outra faixa etária) gostam de jogar videogame; o letramento em games exige o acesso a dispositivos tecnológicos que não costumam ser financeiramente acessíveis. Assim, a transposição da gamificação de contextos culturais educacionais do Norte Global não contempla aspectos particulares do contexto brasileiro. 
Este texto objetiva debater a ausência ou a capacitação insuficiente em letramento em games por parte de professoras e de professores, sem aprofundamento na área de atuação dessas e desses, a partir das observações da autora de que (1) o entendimento comum de docentes é de que gamificação é o uso de jogos (especialmente digitais) em sala de aula, (2) a manutenção da ideia de gamificação como uso de jogo em sala de aula por pesquisadoras e pesquisadores e (3) a falácia compartilhada por defensoras e defensores da gamificação de que ela só pode fornecer resultados positivos.

Essas observações surgiram no contexto profissional da autora que, como pesquisadora de videogames, é parecerista em eventos acadêmicos sobre jogos no contexto educacional e também participa de atividades em diferentes instituições acadêmicas e escolares por meio de palestras e cursos, nos quais pode perceber a repetição de falas de professoras e de professores que estão na situação comentada e não se sentem capacitadas e capacitados para empreender a gamificação em suas salas de aula. Além disso, é pertinente debater, também, algumas questões, possivelmente éticas, da aplicação da gamificação na educação, uma vez que há um certo discurso acrítico, por parte de pesquisadoras e pesquisadores, no que diz respeito à gamificação, tanto por um certo desconhecimento do objeto jogo (analógico e digital) quanto pela romantização de jogo e de videogame (em especial).

\section{Mecânica 2: Movimento em grades}

Em 2009, numa conversa com Jean-Claude Carrière, Umberto Eco (CARRIÈRE; ECO, 2010) afirmou que o livro não vai morrer. Isso era e é evidente, mas a remediação (BOLTER; GRUSIN, 2000) do livro físico para o livro virtual, o e-book, produziu um debate acerca da sobrevivência daquele diante dos recursos oferecidos pela computadorização deste.

Dessa conversa entre Carrièrre e Eco, o que talvez seja de maior interesse para este texto é o entendimento de Eco de que o computador fez com que as pessoas necessitassem aprender, de novo, como ler, agora em uma tela; quer dizer, houve e há a necessidade de adaptação visual e até motora (sem pensar nos outros sentidos que concorrem para a experiência) para a leitura de livros eletrônicos: há dispositivos móveis específicos para isso (como o Kindle da Amazon.com, por exemplo), mas também o celular e o computador servem de suportes para a leitura. $O$ entendimento desse estado das práticas sociais precisa ser relacionado com a crescente exigência de domínio de diferentes linguagens e é por meio do movimento individual e coletivo que essas linguagens vão ser ocupadas.

O e-book deveria ter sido, ou ainda pode ser, o espaço em que o hipertexto melhor se realiza e isso porque o livro eletrônico poderia utilizá-lo de uma forma que o texto impresso não o pode, já que o hipertexto (NELSON, 1993) é um "texto não sequencial que se ramifica e permite escolhas, melhor lido em uma tela interativa... (sendo) uma série de blocos de texto conectados por links que oferecerem ao leitor caminhos diferentes". Os diferentes 
formatos de livro eletrônico não conseguem utilizar o recurso do hipertexto de forma satisfatória e esses formatos não passam de remediação do impresso para o virtual. Mesmo assim, usuárias e usuários desses formatos precisam aprender como utilizar os recursos dessa remediação: marcar o texto; consultar o dicionário no banco de dados; abrir algum eventual link; criar uma biblioteca virtual; etc.

Essa contextualização do livro eletrônico serve para que se pense nas modificações culturais e cognitivas a partir do surgimento de uma nova linguagem (mídia) ou suporte e que exigem um letramento para o uso e o entendimento disso. Porém, o livro digital não diz respeito à simples remediação de uma mídia para a outra, ele oferece, ou deveria oferecer, ferramentas que só a computadorização possibilitam. Quando alguém fala em "letramento em games", está, de fato, se referindo a jogos eletrônicos ou a videogames, até porque jogos concretos sempre estiveram presentes no desenvolvimento dos sujeitos e na educação formal, uma vez que estão inseridos nas diferentes culturas humanas (HUIZINGA, 2000; CAILLOIS, 1986).

Esse letramento, que diz respeito ao tempo contemporâneo, é também o da mídia, descrito por Audi (2014) como "habilidade em reconhecer e utilizar a racionalidade gramatical de uma mídia para gerar e consumir conteúdo". Muitas das vezes, a compreensão dessa gramática se dá de forma mais orgânica; quer dizer, a gramática do sistema é apreendida a partir de interfaces (que devem ser) amigáveis de fácil utilização e aprendizado, um dos objetivos da interação humano-computador.

A existência do letramento em games também é averiguada por Audi, enfatizando "a necessidade de manipular, interagir, interpretar e socializar com as mídias digitais, especificamente o jogo eletrônico" (2014, p. 784). O autor apresenta esse letramento em games pensando em todo e qualquer indivíduo, ou seja, não apenas em um nicho ou faixa etária. Apesar da abordagem acertada nesse sentido, ele naturaliza essa necessidade e, mesmo colocando sua perspectiva como materialista, não debate como as (novas) mídias estruturam as visões das pessoas sobre o mundo ou ainda os contextos sociais e econômicos em que se inserem, o que enfraquece a reflexão dele, inclusive pelo fato de que, para o autor, "o corpo é fator considerável na formação das gramáticas dos meios" (AUDI, 2014, p. 778).

Se o corpo é determinante para formar "gramáticas do meio", então a reflexão precisa ser interseccional e capaz de ir além da compreensão do objeto jogo em si e do próprio conceito de gamificação, levando em conta classe social, localidade, gênero, raça, deficiências, etc. A gamificação, como um modelo de otimização de performance individual, corresponde a uma lógica que é a capitalista, portanto, empreender projetos gamificados na sala de aula é aplicar a lógica capitalista no ensino e na aprendizagem de estudantes. Isso implica entender que a gamificação supõe uma otimização do desempenho do indivíduo tanto pela meritocracia (sistema de recompensas) quanto pela competição, uma das características que defensoras e defensores da gamificação apontam como positiva nesse 
método, o que pode resultar na naturalização de um ciclo da aprendizagem dos indivíduos por meio desse processo, algo já visto com certa contrariedade por quem critica os problemas da gamificação.

Rey (2014) lembra que as pessoas interessadas em gamificação são empresárias, não designers de jogo ou pesquisadoras e pesquisadores, e essas pessoas esperam poder ampliar o mercado de videogames para áreas relacionadas e a gamificação se encaixa nisso. Nesse sentido, o autor amplia a discussão sobre gamificação como uma nova forma de condicionamento para que se pense nela como a padronização de indivíduos que resolvem problemas e se automotivam, desenvolvendo sujeitos que correspondem às necessidades do capitalismo tardio. Por fim, Rey (2014) defende que a gamificação quer se associar à ideia de jogo como algo não produtivo, para assim mascarar sua manipulação ou exploração, que, se fossem evidentes, causariam um desencanto em relação aos sistemas gamificados (REY, 2014, p. 279).

Por outro lado, como afirma Ramirez e Squire (2014), jogos têm muita influência social e cultural e, por esse motivo, a gamificação não deveria ser deixada de lado, como orientam algumas teóricas e alguns teóricos. Assim, defendem que o processo de gamificação não é simples e requer tempo, recursos e projetos cuidadosos por parte de educadores e de educadoras, porém se dedicam a comentar aqueles elementos ditos fundamentais nos jogos, a saber, sistema de pontos, conquistas, tarefas e desafios, e encerram sua reflexão pontuando que devem ser pensadas e utilizadas mecânicas que podem contribuir com os valores e os sentidos que se gostaria de promover. A relevância cultural dos videogames reforça o discurso da gamificação, mas nem sempre se tem em vista aquilo que se quer produzir na sociedade ou, ainda, aquilo que se produzirá pelo uso da gamificação. Por isso, a compreensão sobre o design de jogos deve contribuir para o letramento em games de professoras e professores.

\section{Mecânica 3: Simulação}

No início do texto, afirmou-se que há uma falta de consciência sobre o que vem a ser design de jogo e que isso se relaciona com a não compreensão ou a dificuldade de compreender o que está por trás da gamificação.

Apesar dessa consciência ser fundamental, professoras e professores não precisam, evidentemente, se tornar especialistas em design de jogo, mas, para que possam se inserir no contexto de produção de gamificação, precisam compreender como funciona a rede de elementos que compõe o design de jogo. Essa compreensão pode e deve vir de experiência de jogo e não, apenas, de instrução formal por meio de cursos ou capacitação teórica com alguma exemplificação, mas sem contato com jogo (ou jogos). É na experiência de jogo, ao longo do jogo, que as suas mecânicas são apreendidas pelas jogadoras e pelos jogadores, assim como os possíveis resultados dessas mecânicas. 
No entendimento de Chris Crawford, o "design de jogo requer a criação de sistemas que são interessantes e divertidos para brincar. O mundo é cheio de sistemas." (CRAWFORD, 2003). Nesse sentido, jogos são sistemas como tantos outros no cotidiano, isso quer dizer que seguem regras (que podem ser flexíveis e até quebradas), que apresentam variáveis (interagem com o sistema de jogo tanto elementos externos ao jogo - aquilo que está no mundo cotidiano - quanto internos, como a física do jogo) e que são dinâmicos, pois simulam uma situação que estabelece uma ligação entre o estado inicial e o estado presente do jogo, ou seja, o que foi feito e como resultou no que se observa.

Para que a gamificação passe a fazer sentido para um sujeito, ela precisa ser compreendida dessa forma, como a criação de um sistema que obedece a critérios e apresenta elementos próprios, e o mesmo vale para as mecânicas que podem compô-la, demonstradas em situações reais de jogo para que o indivíduo perceba o porquê disso. Por isso a importância de conhecimento prévio de jogo e de videogame por parte de quem vai desenvolver atividades gamificadas. Mais além, é fundamental que esse conhecimento seja fundamentado a partir de jogos de diferentes gêneros, uma vez que as mecânicas representam traços característicos dos gêneros e costumam ser predominantes, o que tem sido utilizado para criar as categorias de gêneros de jogos a partir do conjunto de mecânicas comuns (COOK, 2005), ainda que alguns possam ser híbridos.

No estado atual da gamificação, há posicionamentos favoráveis e contrários ao seu uso. Walz e Deterding definem que há o grupo de pesquisadoras e pesquisadores otimistas, que consideram o design de jogo, e por extensão a gamificação, como uma solução para os desafios existenciais do século XXI, e o grupo dos "distópicos", que defendem que a gamificação nunca vai gerar as qualidades envolventes de jogos bem projetados (WALZ; DETERDING, 2014).

No grupo otimista, Jane McGonigal defende que, cada vez mais, trabalhadores estadunidenses, o maior mercado de games no mundo, dedicam mais tempo de suas vidas aos videogames e isso significa, para ela, que no "mundo real está faltando algo progressivamente" (2012, p. 3). Considerando isso, ela acredita que as pessoas "devem começar a fazer jogos para consertar o mundo" (2012, p. 9). Ela inclusive defende que mais e mais pessoas estão se identificando com o termo gamer, algo que se discute muito nos últimos anos, não pela estereotipia que se relaciona à palavra, mas por causa do suposto sujeito ideal que tomou para si o título de gamer: homens, predominantemente brancos, de classe média e que reclamam o videogame como deles, afirmando que os jogos foram feitos para eles e mulheres (brancas, negras, latinas, cis, lésbicas, trans, etc.), homens negros e LGBTs não podem exigir espaços nessa mídia, tanto em termos de representação quanto de produção.

No grupo pessimista, lan Bogost afirma que a gamificação é besteira (bullshit), mas não no sentido de tolice, mas, sim, como algo que serve para esconder o valor real e coagir a audiência (BOGOST, 2014). Além disso, ele sugere que gamificação é uma prática de 
profissionais do marketing, que procuram criar e depois explorar uma oportunidade em busca de lucro, e é, ainda, uma prática de persuasão. Surge, a partir dessa perspectiva, a preocupação com o caráter condicionante da gamificação. Apesar dos dois grupos, a dicotomia não é necessariamente estabelecida, pois há interseções em algumas pesquisadoras e alguns pesquisadores. Este texto, no entanto, orienta-se pela perspectiva de Bogost, mas sem deixar de fundamentar a gamificação.

Esses dois grupos ilustram, ainda, que não há consenso na comunidade, tanto de pessoas acadêmicas como não acadêmicas, sobre o que de fato implica o uso da gamificação, inclusive porque existem muito poucas pesquisas empíricas bem desenvolvidas sobre os efeitos dela em ambientes de não jogo (HAMARI, KOIVISTO \& SARSA, 2014). Outra questão que surge nesse contexto é a presença da ideia de que a vida deve ser orientada por aquilo que é agradável (SCHELL, 2010), seja no trabalho ou na educação. É evidente que, por trás dessa premissa, subjaz o condicionamento para que o sujeito queira realizar uma dada atividade, que já se coloca como envolvente e com promessa de recompensa, mesmo que simbólica. Não se pode perder de vista que jogos e videogames são atraentes, também, pela exigência de dedicação do sujeito para que o jogo progrida e essa dinâmica, na gamificação, faz com que as pessoas insistam e se dediquem à atividade, mesmo que ela tenha se tornado uma espécie de trabalho.

Nesse sentido, um projeto ou uma atividade gamificada deveria ser como um sistema para "tornar a aprendizagem e a instrução mais divertidas" (KAPP, 2012), mas, ao mesmo tempo, contemplar a complexidade do design de jogo e não somente o recorte de uma mecânica qualquer para um ambiente de não jogo. A gamificação é a simulação desse sistema a partir de mecânicas de jogo, mas, também, da "estética e pensamento de jogo" fora do jogo. Por isso, a criação de uma atividade de aprendizagem atrelada a um ranking de estudantes com melhor desempenho, por exemplo, não alcança a complexidade de um jogo e, portanto, não contempla os elementos que fazem com que as pessoas joguem e queiram jogar. Essa reflexão costuma escapar de defensoras e defensores da gamificação que, antes de entenderem o objeto jogo, importaram uma metodologia colonial de engajamento para um contexto em que a "cultura" de game ainda está se desenvolvendo e que tem e terá características próprias.

Walz (2006), em seu site Playce, comenta a ludificação da sociedade, em que a experiência com a mídia não é apenas interativa, mas, mais importante, é tátil. $\mathrm{O}$ autor também define o que ele considera ser a "geração dos games": pessoas que cresceram jogando em videogames e computadores e para as quais as referências midiáticas e tecnológicas são ferramentas, mecanismos e padrões de interação desenvolvidos a partir das experiências de entretenimento e das tecnologias da computação. Muitas pessoas fazem parte dessa "geração dos games" e isso pode refletir em como pensam, aprendem, trabalham, estudam e se relacionam com as outras pessoas, mas, embora relevante, essa reflexão não pode ser estendida para todas as pessoas ou todas as localidades da mesma forma em um processo homogeneizante. 
Autoras e autores escrevem sobre diferentes temas em relação aos games, às vezes sobre aprendizagem, sobre saúde, sobre impactos sociais e culturais, sobre processos identitários, etc., outras vezes comparam com o cinema ou com a literatura. Talvez, em parte por isso ou não, muitas vezes parece que games ou videogames constroem uma cultura própria, como se estivessem à parte da cultura dominante. Adrienne Shaw (2010) problematiza isso e defende que é preciso observar o videogame como parte da cultura e que diferentes identidades vão jogar, não apenas aquela que se diz gamer.

No contexto brasileiro, o uso de celular para jogar (PGB, 2018) é muito disseminado entre a população. Isso, na visão de algumas comunidades gamer, é visto com preconceito, pois os indivíduos desses grupos compartilham um imaginário de que só é gamer quem joga em computador ou console e quem joga jogos difíceis. No entanto, esses grupos parecem desconhecer o histórico rebelde e de resistência dos videogames no país.

\section{Mecânica 4: Cooperativo}

Quando se fala em cultura de game ou de videogame, é preciso considerar que, no Brasil, a presença de videogames, tanto jogos quanto consoles, se deu somente por volta de 1977, com a chegada do console Tele-Jogo Philco, enquanto que, nos Estados Unidos, o primeiro jogo de videogame, Tennis for Two, foi criado em 1958 e as máquinas de arcade se popularizaram no início da década de 1970 (NESTERIUK, 2004). Nesse sentido, o videogame, mesmo de uso público e coletivo em shoppings, bares ou restaurantes, adentrou as atividades de lazer da sociedade estadunidense nos grandes centros e nas pequenas cidades. Isso não se repetiu no Brasil.

Videogames sempre foram itens de alto valor financeiro no país e a facilidade de acesso estava nos grandes centros urbanos, especialmente por meio dos fliperamas (arcade games). A história do videogame no Brasil se caracteriza pela rebeldia, pois consoles que não chegavam no Brasil passaram a ser construídos no território nacional por empresas de tecnologia que utilizaram de engenharia reversa para criar os seus consoles.

Além disso, os jogos piratas são uma realidade desde os anos 1980, sendo que o console de PlayStation 2 ainda hoje tem jogos pirateados circulando pelo país, devido à facilidade de modificação. No Brasil, contudo, a pirataria de videogame não se limitou à falsificação somente. Em 2007, por exemplo, foi criado o Bomba Patch, um mod (modificação) baseado no jogo de futebol Winning Eleven 10. A criação do Bomba Patch popularizou o gênero no Brasil no momento em que não apenas oferecia a representação de elementos brasileiros no jogo, mas, também, valores acessíveis e disponibilidade em qualquer banca de camelô, conforme Matheus Fernandes (2018). Talvez, possa-se afirmar, ainda que sem quantificação, que Bomba Patch é "o jogo não-oficial brasileiro mais bem sucedido" (FERNANDES, 2018) e que segue tornando acessível, e 100\% atualizado pela 
Geomatrix Games, o gênero mais jogado no Brasil (PGB, 2018).

O videogame, então, se tornou parte da cultura de mídia brasileira, assim como em outros países, mas essas características históricas não podem ser desconsideradas, pois implicam em como se compreende a presença dos videogames no Brasil. A interpenetração de games nas culturas se relaciona com as histórias particulares de cada comunidade, porém ela se efetua de formas diferentes a partir da localidade. Quer dizer, as dificuldades encontradas no Brasil para o acesso aos consoles e aos videogames impactaram na baixa ou inexistente naturalização da mídia. Assim, grupos com maior poder econômico têm mais facilidade para consumir produtos tecnológicos, mas os outros grupos econômicos nem sempre, ainda que tenham encontrado meios de consumo: na primeira década dos anos 2000, as lan houses serviram tanto para a democratização do acesso à internet quanto para os jogos; as locadoras de jogos também cumpriram papel fundamental, pois alugavam jogos e costumavam ter consoles para que as pessoas, especialmente crianças e jovens, pudessem jogar; e, antes disso, os fliperamas reuniram as máquinas de arcade mais famosas. Outra interseç̧ão nesse histórico é a questão de gênero. Naquela época, era comum ver poucas meninas nesses espaços, ou nenhuma. Ainda hoje, em que as mulheres correspondem a $58,9 \%$ da população que joga no Brasil (PGB, 2018), a questão de gênero merece consideração, pois o gamer, o suposto sujeito ideal do videogame, não sabe lidar com essa presença de mulheres, o que também se reproduz quando as identidades são negras e LGBTs.

Por isso, pode-se pensar que a cultura de games no Brasil tem matizes diferentes e isso se reproduz nas gerações de sujeitos brasileiros, que não necessariamente se desenvolveram com a presença dessa mídia como uma prática social. Nesse sentido, entender que há gerações de professoras e de professores em atividade que não tiveram acesso a jogos eletrônicos ou a consoles é fundamental para compreender que o letramento em games não é algo naturalizado. Portanto, para que essas pessoas possam (se quiserem) implementar modelos gamificados em seus contextos de ensino, é preciso que ocorra o letramento dessa mídia.

Um dos nomes principais sobre a implementação de jogos na educação é James Paul Gee. Ele reforça algumas posições abordadas por outros nomes e define que aprendizagem deve tanto oferecer situações frustrantes quanto satisfatórias e que o ponto fundamental é transformar as atividades difíceis em enriquecedoras (2003, p. 6). O autor apresenta o videogame como um domínio semiótico, entendido como um conjunto de modos diferentes que produzem sentido, como imagens, sons, gráficos, diálogos, objetos e pessoas, não apenas palavras (GEE, 2003, p. 17). Mais além, Gee comenta que, quando faz palestras para professoras e professores (mesmo no contexto estadunidense em que videogames são muito mais presentes), essas pessoas se frustram com a experiência, pois prendem-se apenas à informação verbal do que é apresentado, o que significa que não há compreensão do domínio semiótico do videogame. 
Essa situação abordada por Gee se repete no contexto brasileiro; então, sugerir a gamificação como nova estratégia de ensino e de aprendizagem sem pensar no conhecimento e letramento em games de professoras e professores é propor que essas pessoas ensinem estudantes sem o domínio semiótico dessa linguagem. Por isso, é fundamental debater a ausência ou a capacitação insuficiente em letramento em games por parte de professoras e de professores. Mais, é preciso questionar, diante desse contexto de gamificação, quais são as habilidades necessárias para empreender um projeto desses ou, ainda, quem pode ou poderia implementar a gamificação. Enquanto não se pensar sobre isso, publicações e pesquisas seguirão deixando de lado o professor e a professora e concentrando em como gamificar a educação ou a sala de aula. Talvez, o caminho possível seja a cooperação entre teoria e prática, entre academia, designers de jogo e professores e professoras.

O SBGames ${ }^{2}$ é o principal evento na área de jogos e entretenimento digital da América Latina e é realizado pela Sociedade Brasileira de Computação. Anualmente, o evento reúne cerca de mil pessoas, entre pesquisadores e pesquisadoras, estudantes e empresários e empresárias. Nas últimas cinco edições, de 2014 a 2018, a presença de pesquisas sobre a gamificação ou aplicação de jogos ao ensino cresceu de forma significativa, sendo que, em 2014, apenas um dos trabalhos era sobre gamificação e ensino, enquanto que nas edições mais recentes, 2017 e 2018, foram 20 e 12 trabalhos respectivamente. Visitando os anais do evento desses anos, nas Trilhas de Cultura e de Educação, pode-se observar que a visão predominante apresentada nos trabalhos é da gamificação como uso de jogos (eletrônicos) no ensino. Como comentado no início do texto, essa visão está associada ao entendimento de gamificação e, por isso, não são incomuns relatos de professores e professoras de que gamificar suas salas de aula seria complicado, pois não conhecem nem costumam jogar jogos.

As ofertas de cursos sobre gamificação são diversas e prometem capacitar profissionais de diversas áreas a partir dos princípios básicos da metodologia, ou seja, vão focalizar naquilo que pode ser facilmente transposto dos jogos (o modelo de pontosmedalhas-rankings), transformando isso no núcleo da experiência. Mais além, reforçam o discurso de que vão capacitar participantes para que possam criar situações motivadas pela competição, seja no mercado, seja na educação. Yee, um dos autores que vê a gamificação como promissora, afirma que as pessoas se envolvem mais quando as atividades são competitivas, mas que a competição deve levar para algum lugar, mostrar progresso, ou se torna uma atividade monótona.

O que está por trás de mostrar a competição como um dos elementos fundamentais da gamificação, ou mecânica de jogo, é sugerir uma ação que não exige profundo conhecimento para ser implementada, ou seja, é fácil criar uma atividade competitiva. Porém, atividades competitivas não são propostas enriquecedoras para aprendizagem em

\footnotetext{
${ }^{2}$ Site SBGames: $\underline{\text { https://www.sbgames.org/ }}$
} 
sala de aula, pois só se sentirá motivado quem costuma se sair melhor, criando uma estrutura de pirâmide em que: quem está no topo não tem como ir além; quem está no meio até encontra alguma motivação para alcançar o topo; e quem está na base, e não percebe progresso em sua performance, não se motivará. A competição é característica evidente nas sociedades capitalistas e as dificuldades são compreendidas como muito trabalhosas de se superar, justamente porque se entende a intersecção de diferentes camadas e opressões, e os modelos de atividades competitivas só reforçam isso, pois se baseiam em quem é melhor e pior e categorizam as pessoas em linhas de melhores e de piores (GEE, 2003, p. 164).

Portanto, antes de pensar em gamificar a sala de aula, professoras e professores devem passar por um letramento em games que capacite para um conhecimento amplo do domínio semiótico do videogame. Da mesma forma que as licenciaturas promovem o desenvolvimento didático de seus estudantes pela familiarização com diferentes linguagens e mídias já estabelecidas, o mesmo deve ser pensado para os videogames. É preciso que professoras e professores assinem um contrato com os jogos, com a experiência de jogo, para que possam comunicar isso no seu ensino.

Conforme sugere Audi (2014), forma-se um contrato entre jogadores e jogos, mas esse contrato não se estabelece necessariamente pelo tutorial, como o autor sugere, pois há jogos que apresentam isso ou não. Antes, o contrato entre jogadores e jogos se dá pela experiência com gêneros diferentes, os quais demonstram as variedades que videogames podem apresentar e, também, as suas mecânicas. A generalização proposta pelo autor, de que esse contrato possui "as regras, a narrativa, os personagens, os objetivos, os comandos da interface", etc., invisibiliza gêneros em que as regras são mínimas, em que não há narrativa, em que não há personagens nem objetivos, só para mencionar alguns elementos que entram na consideração quando se pensa em gêneros e não em jogos específicos.

O letramento em games não pode ou não deveria ser pensado como a capacidade de interpretar um jogo particular, mas, sim, a capacidade de interpretar gêneros de jogos, para que as mecânicas por trás de cada gênero se tornem evidentes e possam, então, ser transpostas para situações fora do ambiente de jogo, caso professoras e professores tenham esse interesse. Além disso, o letramento em games, como um dos letramentos fundamentais nas sociedades atuais, deve ser capaz de construir pontes mesmo quando os sujeitos não têm o videogame como uma de suas práticas sociais e isso vale tanto para professoras e professores quanto para estudantes, uma vez que, com maior ou menor interpenetração, os jogos eletrônicos estão presentes no cotidiano, seja em celulares, computadores, tablets ou consoles.

Estabelecer como premissa a ideia de que todas as pessoas jogam videogame e se interessam por ele é desconsiderar a materialidade da mídia, no sentido de que: ela é considerada recente (não está tão normalizada); não é de fácil acesso, pois exige alguma plataforma e isso representa investimento financeiro; e não faz parte das linguagens socializadas e naturalizadas pela educação, como o livro, o cinema, o jornal, o quadrinho, etc. 
Por outro lado, também não se deve tomar como posicionamento o pensamento de que, se nem todas as pessoas jogam, videogame não é relevante de ser aprendido. Portanto, é na cooperação entre diferentes peças (jogadores usuais, não tão usuais e não jogadores), com diferentes conhecimentos e acessos em relação aos jogos que o letramento em games pode acontecer.

\section{Mecânica final: Jogo em Equipe}

O debate sobre a ausência ou a capacitação insuficiente em letramento em games por parte de professoras e de professores tornou-se aparente diante das considerações levantadas no texto, assim como algumas questões, talvez éticas, da aplicação da gamificação na educação, especialmente no que diz respeito à compreensão da gamificação como uma metodologia condicionante e coerciva que se insere de forma sutil no contexto capitalista de produção de saberes e de trabalho.

A partir de reflexões sobre a gamificação e o letramento em games, mas também de questões sociais, históricas, culturais e econômicas, os princípios que fundamentam a gamificação se mostraram, o que permite, com base na perspectiva apresentada, um entendimento mais objetivo e menos romantizado do uso da gamificação, por vezes defendida como a grande estratégia de transformação do mundo. O que não se comenta nessa ideia de transformação do mundo é que essa utopia em vista é o do sistema capitalista do Norte Global, em que as atividades de jogo foram comodificadas (commodified) em trabalho.

Entende-se, com o debate apresentado, que o letramento em games deve anteceder qualquer movimento em direção à gamificação, pois é preciso saber interpretar o domínio semiótico do videogame por meio do reconhecimento e do uso da sua gramática, compreendida como a estrutura de funcionamento da mídia em seus diferentes gêneros, para que se torne possível consumir e criar conteúdo.

Essa gramática é composta, em parte, pelas mecânicas que caracterizam os jogos e não somente aquelas que são mais simples, mais evidentes ou mais fáceis de transposição, o tal modelo de pontos-medalhas-rankings (HAMARI; KOIVISTO; SARSA, 2014). Por isso, é na experiência de jogo que uma pessoa desenvolve o reconhecimento de tal gramática e se torna capacitada para utilizá-la. Nesse sentido, é preciso que se crie um ambiente abstrato de jogo em equipe entre academia, designers de jogo e professoras e professores e essa equipe deve possibilitar o diálogo entre os diferentes saberes e particularidades. Talvez, até, essa equipe deve chamar para si os saberes de estudantes de diferentes níveis e que podem contribuir com a cultura de game que se desenvolve no Brasil, considerando que grande parte dessas pessoas se insere na "geração dos games".

Por fim, este texto reconhece a necessidade de debater o conceito mesmo de 
gamificação, e também o de letramento em games, no sentido de elucidar especialmente os problemas que ele apresenta, tanto pelo reducionismo das aplicações quanto por aquilo que se mascara na sua aparente positividade. Além disso, apesar de considerar a metodologia de gamificação como uma nova forma para fazer com que as pessoas produzam mais em qualquer contexto, a autora deste texto compreende que a gamificação não será abandonada tão cedo por suas defensoras e seus defensores e que, antes de ignorar o seu uso, prefere contribuir criticamente com as aplicações e seus desdobramentos, apontando para a necessidade de letramento em games por parte de docentes.

\section{Referências}

AUDI, Gustavo. Letramento em games: o aprendizado na utilização de novos meios. Linguagem \& Ensino, Pelotas, v. 17, n. 3, p. 777-796, set./dez. 2014.

BOGOST, lan. Why Gamification is Bullshit. In: WALZ, STEFFEN P.; DETERDING, SEBASTIAN (ed.). The Gameful World: approaches, issues, applications. Massachusetts: MIT Press, 2014.

BOLTER, Jay David; GRUSIN, Richard. Remediation: understanding new media. Cambridge: The MIT Press, 2000.

CAILLOIS, Roger. Los Juegos y Los Hombres: la máscara y el vértigo. México: Fondo de Cultura Económica, 1986.

COOK, Daniel. Game Genre Lifecycle: part I. 2005 Disponível em: http://www.lostgarden.com/2005/05/game-genre-lifecycle-part-i.html. Acesso em: 15 mar. 2019.

CARRIÈRE, Jean-Claude; ECO, Umberto. Não contem com o fim do livro. Rio de Janeiro: Record, 2010.

CRAWFORD, Chris. On Game Design. Indiana: New Riders, 2003.

FADEL, Luciane Maria; ULBRICHT, Vania Ribas; BATISTA, Claudia Regina; VANZIN, Tarcísio (org.). Gamificação na Educação. São Paulo: Pimenta Cultural, 2014.

FERNANDES, Matheus. Como o Bomba Patch formou uma geração que consome futebol pelo videogame. Vice, Brasil, 5 jul. 2018. Disponível em: https://www.vice.com/pt br/article/qvngj5/bomba-patch-historia-futebol-videogame.

Acesso em: 20 out. 2019.

GEE, James Paul. What Video Games Have to Teach Us about Learning and Literacy. New York: Palgrave MacMillan, 2003. https://doi.org/10.1145/950566.950595

HAMARI, Juho; KOIVISTO, Jonna; SARSA, Harri. Does gamification work? A literature review of empirical studies on gamification. In: HAWAII INTERNATIONAL CONFERENCE ON SYSTEM SCIENCES, 47., 2014, Hawaii. Proceedings [...]. Washington, DC: IEEE Computer Society Press, 2014. https://doi.org/10.1109/HICSS.2014.377

HUIZINGA, Johan. Homo Ludens. 4. ed. São Paulo: Perspectiva, 2000.

KAPP, Karl M. The Gamification of Learning and Instruction: game-based methods and 
strategies for training and education. San Francisco, CA: Pfeiffer/ASTD, 2012. https://doi.org/10.1145/2207270.2211316

MCGONIGAL, Jane. Reality Is Broken: why games make us better and how they can change the world. New York: Penguin, 2012.

NELSON, Theodor Holm. Literary Machines. Sausalito: Mindful Press, 1993.

NESTERIUK, Sérgio. Breve considerações acerca do videogame. In: INTERCOM, 17., 2004, Porto Alegre. Anais eletrônicos [...]. Disponível em: http://www.intercom.org.br/papers/nacionais/2004/resumos/R1120-1.pdf. Acesso em: 15 mar. 2019.

O MERCADO Informal de Video Games no Brasil, 2017. (18 min $39 \mathrm{seg}$ ). Publicado pelo canal Cloth Map. Disponível em: https://youtu.be/MU29Wqg BVo. Acesso em: 15 mar. 2019.

PGB. Pesquisa Game Brasil Insights 2018. 2018. Disponível em: https://materiais.pesquisagamebrasil.com.br/insights-2018. Acesso em: 15 mar. 2019.

RAMIREZ, Dennis; SQUIRE, Kurt. Gamification and Learning. In: WALZ, STEFFEN P.; DETERDING, SEBASTIAN (ed.). The Gameful World: approaches, issues, applications. Massachusetts: MIT Press, 2014. p. 629-652.

REY, PJ. Gamification and Post-Fordist Capitalism. In: WALZ, STEFFEN P.; DETERDING, SEBASTIAN (ed.). The Gameful World: approaches, issues, applications. Massachusetts: MIT Press, 2014. p. 277-295.

ROBERTSON, Margaret. Can't play, won't play. In: Hide \& Seek, 2010. Disponível em: http://hideandseek.net/2010/10/06/cant-play-wont-play/. Acesso em: 13 maio 2019.

SANTAELLA, Lucia. NESTERIUK, Sérgio. FAVA, Fabricio (ed.). Gamificação em Debate. São Paulo: Blucher, 2018.

SHAW, Adrienne. (2010). What Is Video Game Culture? Cultural Studies and Game Studies. Games and Culture, v. 5, n. 4, p. 403-424. 2010. https://doi.org/10.1177/1555412009360414 DESIGN Outside the Box. Publicado por Yunjia Li, 16 fev. 2015. (28 min $18 \mathrm{seg}$ ). Palestra de Jesse Schell. 2010. Disponível em: https://youtu.be/nG PbHVW5cQ. Acesso em: 12 mar. 2019.

WALZ, Steffen P. Welcome to my playce. 2006. Disponível em: http://spw.playbe.com. Acesso em: 15 mar. 2019.

WALZ, Steffen P.; DETERDING, Sebastian. An introduction to the gameful world. In: WALZ, STEFFEN P.; DETERDING, SEBASTIAN (ed.). The Gameful World: approaches, issues, applications. Massachusetts: MIT Press, $2014 . \quad$ p. 1-14. https://doi.org/10.7551/mitpress/9788.001.0001

WOLF, Gary Isaac. Quantified self. In: Aether, 2009. Disponível em: http://web.archive.org/web/20091106094426/http://aether.com/quantifiedself. Acesso em: 22 mar. 2019.

Recebido em: 09/06/2019

Aceito em: $27 / 10 / 2019$ 